\title{
MITO Y ARGUMENTACIÓN
}

\author{
Myth and argument
}

\section{Henry Campos*}

\section{RESUMEN}

El presente artículo ofrece una aproximación al mito como argumento. Por ejemplo, el mito, en algunos contextos, puede ser usado como criterio de verdad, argumento de autoridad, ejemplo, causa de un fenómeno, término de una analogía, alegoría, o un medio para explicar una tesis.

Palabras clave: Mito, argumento, lógica, verdad, literatura.

\begin{abstract}
This paper offers an approach to the myth as argument. For example, in some contexts myth can be used as criteria of truth, authority argument, exemplum, cause of a phenomenon, term of an analogy, allegory and a mean in order to explain a thesis.
\end{abstract}

Key Words: myth, argument, logic, truth, literature.

\footnotetext{
*Universidad de Costa Rica. Profesor de la Escuela de Filología, Lingüística y Literatura. Costa Rica. Correo electrónico: hcamposv@yahoo.es Recepción: 26-04-2017 Aceptación: 12-05-2017
} 
Para los efectos del presente análisis se han identificado, grosso modo, dos marcos de referencia básicos:

1) Una visión mítica del mundo, y

2) Una visión racionalista del mundo

En una visión mítica del mundo, el universo es interpretado y vivido en función de una serie de discursos que forman parte importante de la cultura de un pueblo, estos discursos por lo general han sido transmitidos de generación en generación, lo que redunda en la conformación de un principio de autoridad: el conjunto de este proceso da lugar, a nivel argumentativo, en lo que bien puede denominarse como argumentación mítica.

Por su parte, una visión racionalista del mundo no se ve satisfecha con la perspectiva precedente, por lo que tiende a exigir una argumentación más rigurosa a los discursos que pretenden explicar el por qué del universo.

Estas visiones no son excluyentes entre sí. Así, la teología cristiana pretende ser un puente de comunicación entre la religión y la razón humana, lo cual puede ocurrir también en ambientes cultos e intelectuales del mundo islámico. Sin embargo, aunque en la argumentación mítica las narraciones tienden a tener un valor argumentativo per se, en la argumentación racional este valor es cuestionado y únicamente se le reconocerá algún valor en determinados contextos.

Considérese, por ejemplo, la siguiente situación argumentativa en la que se discute el celibato sacerdotal en la iglesia católica occidental:

Diego: El celibato no es algo esencial al sacerdocio: en la iglesia oriental los sacerdotes se casan sin ningún problema.

Joaquín: El Papa ha explicado que esta condición permite a los sacerdotes identificarse más perfectamente con Jesucristo.

Joaquín apela a una autoridad (el Papa) que a su vez refuerza la tesis lo óptimo es que los sacerdotes se identifiquen más perfectamente con Jesucristo. 
Es obvio que la referencia al Papa tiene distintos valores argumentativos en función del contexto social en que se encuentre. Así, ante un enemigo del catolicismo, se podría generar una animadversión inmediata que incluso podría llevar a que no se considere racionalmente la afirmación sostenida. Podrían esperarse también expresiones sarcásticas, burlonas o irónicas. En cambio, frente a un creyente conservador, representaría un indicador de que la discusión ha terminado, pues habrá de aceptar la afirmación sin cuestionamiento alguno.

Otro tipo de interlocutor podría exigir más profundidad en la explicación, alguna referencia para confirmar la afirmación o, mejor aún, retomar el contraejemplo de la iglesia oriental para continuar con la discusión y descubrir que, entonces, se trata de una disposición normativa que puede ser modificada.

¿Por qué estas diferencias en la valoración de un mismo evento argumentativo? Esto parece derivarse de que:

El convencimiento o la persuasión en una situación argumentativa dependen en buena parte, como es sabido, de la apariencia y de las habilidades lingüísticas de los protagonistas, de la manipulación de la información, del tipo de argumentos aportados, pero también de predisposiciones emotivas. (Lo Cascio, 1998, p. 39)

Ciertamente, los conceptos de "argumento" y "argumentación” son muy disímiles entre sí. Si en una discusión intervinieran únicamente argumentos, no solo sería más fácil su análisis y evaluación, sino que, posiblemente, podría llegarse más pronto a una solución. Sin embargo, una discusión, así como cualquier otro tipo de interacción comunicativa, involucra más aspectos, los cuales forman parte de la "argumentación", ya que:

Se puede hacer una distinción útil entre argumento y argumentación. En el argumento consideramos únicamente los aspectos lógicos, que tienen que ver con la validez o invalidez del razonamiento. En la argumentación se consideran otros aspectos, como los psicológicos (ironía, ridículo, aplomo, amenazas, etc.) y sociológicos (propaganda, consenso, etc.). La argumentación rodea al argumento. (Camacho, 2009, p. 19) 
Nótese que aquí se asume un concepto lato de argumentación. Para efectos de claridad, con Lo Cascio se considera que:

Un texto es argumentativo solo si contiene explícitamente formulados una tesis y al menos un dato que la justifique. (1998, p. 41)

Ahora bien, el papel que el mito pueda desempeñar en un proceso argumentativo está en función del sistema de creencias y expectativas de los sujetos involucrados, por lo que es de sumo interés identificar cómo esas creencias pueden incidir y modificar su valor.

\section{La argumentación mítica en la visión mítica del mundo}

En su Nueva ciencia, Vico comprendió claramente que:

El principio de tales orígenes de las lenguas y de las letras es que los primeros pueblos del gentilismo, por una demostrada necesidad de naturaleza, fueron poetas, que hablaron mediante caracteres poéticos, descubrimiento que es la llave maestra de esta ciencia, el cual nos ha costado la obstinada investigación de casi toda nuestra vida literaria, ya que desde nuestra naturaleza civilizada es de hecho imposible de imaginar, y solo con gran esfuerzo nos es posible comprender semejante naturaleza poética de tales hombres primitivos. (1985, p. 56-57, [34])

Al contrastar y relativizar el punto de vista de su época con el "primitivo", Vico descubre que en los mitos estuvieran escondidos los misterios de la susodicha sabiduría vulgar (ibid, 58, [37]) y reconoce que la alegoría contiene un sentido no ya análogo sino unívoco, no ya filosófico sino histórico, de aquellos tiempos de los pueblos de Grecia (ibid, 57, [34]).

Hans Blumenberg, en esta línea de pensamiento, afirma la validez propia del mito frente a la idea de concebirlo como una "metáfora absoluta" ya que:

el mito lleva la sanción de su procedencia antiquísima e insondable, de su legitimación divina o inspiracional; mientras que la metáfora no tiene más remedio que presentarse como ficción, y su única justificación consiste en el hecho de hacer legible una posibilidad del comprender. (citado por Rivera García, 2010, p. 149) 
En toda argumentación, como indica Humberto Eco, intervienen fuerzas externas de naturaleza suasoria. En la cultura occidental contemporánea, el mito formaría parte de estas fuerzas. Sin embargo, cuando dicha fuerza mítica es parte del sistema de valores que legitiman el discurso argumentativo, el problema se torna sumamente complejo.

Dichas potencias las vemos operar en muchos contextos y de maneras muy diversas. Por ejemplo, al interpretar nuestra relación con la realidad. Para ilustrar esto considérese el siguiente ejemplo extraído de la Ilíada, cuando Zeus, en el canto segundo, envía al Ensueño con una misión al campo de los aqueos. Esta divinidad se presenta y encuentra a Agamenón dormido y se le aparece en sus sueños con la figura de Néstor, hijo de Neleo y rey de Pilo, el más viejo, sabio y elocuente caudillo de los aqueos. Al despertarse, Agamenón convoca al consejo de ancianos ante el que manifiesta:

"Oídme, amigos, el divino Ensueño, / llegó a mí entre sueños / a lo largo de la divina noche, / y al divino Néstor sobre todo, / por su aspecto, su talla y su tamaño, /se parecía extremadamente. / Y luego por encima se posó /de mi cabeza y dijo estas palabras: / ¿Duermes, hijo de Atreo el valeroso / domador de caballos? / No es debido que duerma / la noche entera varón consejero / al que huestes están encomendadas / y cuidados preocupan de continuo. / Pero entiéndeme ahora prestamente, / pues de Zeus para ti soy mensajero, / que de ti, aunque esté lejos, / grandemente se cuida y compadece. / Él ordenó que armaras / con toda rapidez a los aqueos / de larga cabellera en sus cabezas; / pues tú ahora conquistar podrías / la ciudad de anchas calles / de los troyanos, porque ya no albergan / pareceres contrarios uno al otro / los dioses inmortales / que en el Olimpo tienen sus moradas, / pues Hera con sus ruegos a todos los doblegó / y cuitas penden sobre los troyanos / de la mano de Zeus suspendidas. / Mas tú en tus mientes tenlo bien cogido". I

Habiendo dicho así, se marchó al vuelo, / y a mí me dejó suelto el dulce sueño. / Pero, ¡venga!, a ver si de algún modo / podemos a los hijos / armar de los aqueos. / Yo les voy a tentar, primeramente, / con palabras que es cosa de uso, / y ordenaré que huyan con sus naves / de numerosas filas de remeros; / vosotros, cada uno por su lado, / con palabras tratad de retenerlos". (Homero, 1995, p. 81-82, versos 57-76, la diagonal separa cada verso del poema) 
Agamenón participa de la visión mítica del mundo, la cual condiciona su forma de interpretar el mundo. Por eso cree firmemente en su sueño y, sobre la base de esta confianza, elabora el plan para armar a sus hombres. En su sistema de creencias están dos premisas básicas: a) Si un dios se comunica conmigo, entonces debo creer en su mensaje y, b) los dioses pueden comunicarse a través de sueños.

Los sistemas de creencias de este tipo, al igual que las supersticiones (aunque sean conceptos diferentes) operan con una forma lógica semejante, el modus ponens. Aquello en que se cree tiene una forma condicional, por ejemplo, si rompo un espejo de vidrio, entonces tendré siete años de mala suerte, proposición que se asume verdadera. Luego, ante la eventualidad de que se rompa un espejo, se incorpora otra premisa, la cual es "también" verdadera, a saber, he roto un espejo, de ahí deviene apodícticamente la conclusión, tendré siete años de mala suerte, conclusión que es aterradora, pues, supuesta la verdad de las premisas, ante un razonamiento válido como el presente, la conclusión es necesariamente verdadera (en realidad, este tipo de proposiciones es objeto de la lógica deóntica, pero con el propósito de simplificar la exposición se ha optado por esta interpretación).

Algo semejante ocurre ante las creencias míticas: aquello en que se cree tiene forma condicional y se asume como cierto, luego, ante un evento de la clase prevista en el antecedente de la anterior proposición condicional, la conclusión deviene apodícticamente verdadera: el sujeto (creyente) está obligado a creer en la verdad de su conclusión.

En el ejemplo, los compañeros de asamblea comulgan de alguna manera con dicha visión, tal y como se desprende de la contestación de Néstor:

“Amigos, consejeros y caudillos / de las huestes argivas, si algún otro / de entre los aqueos ese sueño / nos hubiera contado, / podríamos mentira declararlo / y de él aún más aparte colocamos. / Ahora bien, lo vio / quien se jacta de ser / con mucho el mejor de los aqueos, / pero, ¡venga!, a ver si de algún modo / podemos a los hijos / armar de los aqueos". (Homero, 1995, p. 82, versos 79-83)

El ethos de Agamenón ha contribuido a eliminar cualquier duda, no sobre la creencia (los dioses se comunican por sueños) al validar su visión, sino sobre la veracidad de la experiencia (Agamenón ha tenido un sueño inspirado por los dioses). 
Fuera del contexto de la narración es posible cuestionarse sobre la intención de Homero en este pasaje, dado que se sabía que era un ardid ideado por Zeus contra Agamenón. ¿Por qué Homero presenta un caso en el que los dioses engañan a los hombres? La única respuesta que parece admisible sería: para mostrar que una de las antiguas creencias (parte de las premisas en todo este razonamiento) no es cierta, a saber que si un dios se comunica conmigo, entonces debo creer en su mensaje, porque los dioses mienten y engañan a los hombres.

En el pasaje de la Ilíada, Zeus se ha aprovechado dolosamente de la errónea inteligencia de Agamenón respecto de la voluntad de los dioses. La interpretación de esta voluntad es todo un problema que puede examinarse con ayuda de la lógica; para ello, conviene emplear la noción de una equivalencia lógica conocida como transposición, la cual se aplicará a las proposiciones "los dioses quieren algo" y "algo ocurre". Represéntese "los dioses quieren algo" mediante "p" y "algo ocurre" mediante "q". Es usual pensar que si los dioses quieren algo, entonces ese algo ocurre, lo cual se representaría $\mathrm{p} \rightarrow \mathrm{q}$, donde $\rightarrow$ es la implicación material, leída como "implica”.

Ahora bien, la regla de transposición permite permutar la posición de "p" y "q" negándolas

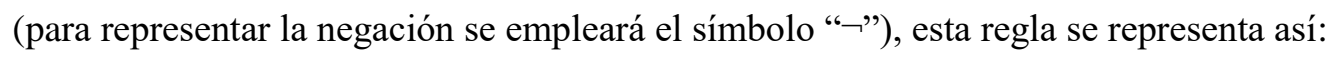

$$
(\mathrm{p} \rightarrow \mathrm{q}) \leftrightarrow(\neg \mathrm{q} \rightarrow \neg \mathrm{p})
$$

que en el ejemplo puede leerse como "si los dioses quieren algo, entonces algo ocurre" es equivalente a "si algo no ocurre entonces los dioses no lo quieren" (se ha introducido el símbolo “↔” que se lee "es equivalente a").

Nótese que esta regla expresa que dado un condicional, el valor de verdad se conserva al invertir la posición y negar simultáneamente sus proposiciones. Ahora bien, la validez de la aplicación de esta regla no comporta que el contenido de sus proposiciones sea verdadero.

Una equivalencia de esta naturaleza se aprecia en Aulularia, de Plauto, durante la escena en que Licónides se aproxima a Euclión y confiesa haber violado a la hija de este último, se suscita una confusión, ya que Euclión cree que Licónides habla de su olla de oro, la cual ha desaparecido. El diálogo es el siguiente:

EVCLIO. Cur id ausu's facere, ut id quod non tuom esset tangeres?

LYCONIDES. Quid vis fieri? factum est illud: fieri infectum non potest. 
Deos credo voluisse; nam ni vellent, non fieret, scio.

EVCLIO. At ego deos credo voluisse ut apud me te in nervo enicem (1988, p. 740-743, la traducción siguiente es del autor).

EUCLIÓN: ¿Por qué osaste hacer esto y tocaste aquello que no era tuyo?

LICÓNIDES: ¿Qué quieres que haga? Ya está hecho y no puede ser desecho.

Creo que los dioses lo quisieron, pues sé que si no lo hubieran querido, no habría ocurrido.

EUCLIÓN: Pues yo creo que los dioses quieren que te haga morir en el potro junto a mi casa.

La tesis de Licónides se enuncia así: si los dioses no quisieran algo $(\neg q)$, entonces no habría ocurrido $(\neg 0)$, lo cual se formaliza de la siguiente manera: $\neg \mathrm{q} \rightarrow \neg \mathrm{o}$, lo cual, por transposición, es equivalente a o $\rightarrow$ q, que significa: si algo ocurre, entonces los dioses lo han querido, que es precisamente la defensa de Licónides. Nuevamente, tal y como se ha insistido supra, se trata de validez lógica, que no de verdad.

Tal creencia de Licónides es común a modelos de visión mítica del mundo.

Otro tipo de argumentación mítica es la ofrecida por Fénix a Aquiles en el episodio de la Embajada (Canto IX de la Ilíada en Homero, 1995, p. 430-606, versos 434-605). Debido a su cólera, Aquiles se había alejado del combate. Con el propósito de hacerlo mudar de opinión, fueron enviados Odiseo, Fénix y Ayax. Fénix incorpora el mito de Meleagro en el elenco de su argumentación: Ártemis castigó a Eneo, rey de los etolios de Calidón, enviando un terrible jabalí a dicha tierra por haberla olvidado al tributar sacrificios a todos los dioses. Como Meleagro logró matar a la temible bestia, Ártemis suscitó una pugna entre los etolios y los curetes (que habían participado en la empresa) por la piel y la cabeza del animal. Durante la batalla, Meleagro hirió de muerte a los hermanos de su madre, por lo que ella lo maldijo, lo cual suscitó que él se retirara del combate, el cual se había desarrollado a favor de los etolos mientras combatía Meleagro. Debido a esto, los curetes llegaron a aproximarse peligrosamente a las torres de la ciudad, pero Meleagro no reaccionaba: 
Y entonces ya a Meleagro su esposa / de hermosa cintura suplicaba / entre lamentos, y le enumeró las aflicciones todas que resultan / a los hombres cuya villa es tomada: / matan a los varones, y el fuego / reduce a cenizas la ciudad, y gente extraña arrastra a los hijos / y a las mujeres de estrecha cintura. / Y su ánimo, al oír esos horrores, se iba conmoviendo, / y en marcha se puso, y se vistió, ajustándosela al cuerpo, / de su resplandeciente armadura. / Así defendió él a los etolos / del día del desastre, / a su ánimo cediendo; pues los dones, / muchos y agradables, todavía / no se le habían hecho realidad, / pero aun así les libró del desastre. / ¡Ea, pues, tú atiéndeme!, no pienses / en tus mientes así, / y que un dios, amigo, no te induzca, / a ese punto, pues peor sería / las naves defender si a arder llegaran; / por el contrario, vete ya a buscar/los regalos, pues a ti van a honrarte / los aqueos igual que a un dios; / que si en la guerra que varones mata / llegas a entrar sin tomar los regalos, / no serás ya estimado de igual modo, / aunque hayas la guerra rechazado". (Homero, 1995, p. 390-391, versos 590-606)

Fénix se ha servido del exemplum mítico para modelar la conducta de Aquiles. Presenta un caso semejante al de este héroe, en el que un renombrado guerrero entra en cólera, como él, y se niega a combatir. Muestra que Meleagro dilató sobremanera su participación, lo cual ocasionó severos daños a su pueblo, pero, aún así, estuvo anuente a cambiar su postura.

Una conducta no solo semejante, sino mejor, se espera del Pelida, pues la argumentación pretende que retome las armas, pero no de manera que el retraso llegue, como en el caso de Meleagro, a poner en peligro la seguridad de su pueblo.

Muy distinta es la función argumentativa del mito en obras como Aitía, de Calímaco, Metamorfosis, de Ovidio, o Biblioteca Mitológica, de Apolodoro. En ellas, el mito asume un papel fundamental, explica (de ahí su carácter argumentativo), un fenómeno físico, una práctica social, etcétera.

De acuerdo con los escolios y los propios fragmentos conservados de Aitía, en esta obra Calímaco formula preguntas sucesivas a las Musas, quienes le responden. Por ejemplo, el fragmento 3 de esta obra, referido a Las Gracias, inicia: (...) cómo sin 〈flautas〉 ni guirnaldas ha placido a los de Paros hacer sus sacrificios (1980, p. 142). El compositor de la obra contesta que tal costumbre tiene origen divino, tal y como se desprende de los escasos textos conservados: 
(...) Y sobre la cerviz de las islas echó Minos oneroso yugo ...

(...) Comenzó por arrojar las primicias de la víctima ...

... Y dijeron, otros que las dio a luz la Titánide Eurínome...

... Desnudas, como vinisteis del vientre de vuestra madre cuando así lo quiso Ilitía. Mas en Paros con mantos y rutilantes vestidos purpúreos... y de continuo destilan aceite vuestros bucles. Sedme ahora propicias y aplicad a mis versos las unidas manos para que por muchos años sobrevivan. (1980, p. 142-143, fragmentos 4-7)

Tal estilo es característico de Calímaco, lo cual se aprecia en su narración sobre el regreso de los Argonautas y el rito de Ánafe y Lindos:

¿Y cómo, diosas, la gente de Ánafe y la ciudad de Lindos con <groserías> y <malsonantes dichos> practican sacrificios, ...a Heracles venera? ...<Así> Calíope dio comienzo: “Al resplandeciente y a Ánafe, vecina de Tera la laconia, y a los Minios, ponlos primero de todo en tu memoria, arrancando del punto en que los héroes navegaban de retorno desde Eetes, rey de Cita, proa a la antigua Hemonía... Y él, de que vio la obra de su hija... pronunció estas palabras: “...y en todo ha habido traición... de escarnio hiciéronme objeto... <la nave> que los porta y los hombres con ella... Séame Helios testigo y el Fáside, rey (de nuestros ríos)". (ibid, 144-145, fragmento 7)

Una lógica semejante se encuentra en Ovidio:

Contempla a éste, que azuza hacia las redes a los asustadizos ciervos, la habladora ninfa, que no aprendió a callar ante el que habla ni a hablar ella misma antes, la resonante Eco. Hasta ahora, Eco era un cuerpo, no una voz; pero, parlanchina, no tenía otro uso de su boca que el que ahora tiene, el poder repetir de entre muchas las últimas palabras. Esto lo había llevado a cabo Juno, porque, cuando tenía la posibilidad de sorprender a las ninfas que yacían en el monte a menudo bajo su Júpiter, ella, astuta, retenía a la diosa con su larga conversación, hasta que las ninfas pudieran escapar. Cuando la Saturnia se dio cuenta de esto, dijo: "De esa lengua, con la que he sido burlada, se te concederá una mínima facultad y un muy limitado uso de la palabra", y con la realidad confirma las amenazas, ésta, sin embargo, duplica las voces al final del discurso y devuelve las palabras que ha oído. (1997, p. 294, versos 356-370) 
La narración anterior explica el origen del eco que, de acuerdo con el mito, sería el producto de un castigo de Juno impuesto a una habladora ninfa. Es razonable pensar que, ante la pregunta de un pequeño sobre qué es el eco, su tutor, madre o padre contestara con este mito; y que el pequeño se sintiera satisfecho con la explicación.

Considérese otro ejemplo: Narra Apolodoro que cuando Zeus decidió destruir la raza de bronce, Deucalión, hijo de Prometeo, construyó un arca:

(...) después de ser trasportado en el arca a través del mar durante nueve días y otras tantas noches, tocó tierra en el Parnaso, y allí, desembarcando al remitir las lluvias, ofreció un sacrificio en honor de Zeus, protector de la huida. Zeus, enviando junto a él a Hermes, le otorgó que tomara lo que deseara y él escogió poseer hombres. Como Zeus asistiera, cogió unas piedras y las lanzó por encima de su cabeza, y las piedras que lanzaba Deucalión se convertían en hombres, y las que lanzaba Pirra, en mujeres. Por esto metafóricamente se llamó al pueblo "laos", de "laas", "piedra". (2004, p. 53, I, 7.2)

En estos últimos ejemplos, el papel del mito en la argumentación corresponde con la noción más extendida de "mito", a saber, narración que contiene un principio explicativo de orden cósmico, social, natural... Desde esta perspectiva, el mito en sí mismo responde a un principio argumentativo pues, de alguna manera, racionaliza, a su manera, el universo.

Los retóricos de la antigüedad conocían esta característica del mito. Menandro el Rétor en uno de sus tratados de retórica epidíctica señala al respecto:

Del tipo mítico y genealógico (se refiere a los himnos) suele con frecuencia servirse todo el que relata nacimientos de dioses y explica a partir de mitos cuántos bienes han proporcionado ellos a los hombres. (1996, p. 92, 333.29-32)

Si bien cualquier pensador moderno podría argumentar que se trata de una instancia de la falacia de causa falsa, es pertinente reconocer que en la visión mítica del mundo hay otros criterios de validación. Nótese a este respecto que el mito, en este ámbito, es el criterio de verdad, por lo que, desde un punto de vista veritativo-funcional, es siempre verdadero.

La pretensión de verdad del mito es un común denominador a todos los sistemas de creencias de este tipo. Esto, aunado al hecho de que no pocos mitos son claros aitía (narraciones de causas), deja entrever un problema lógico. 
Tal y como se vio, numerosos autores desarrollan este valor: el por qué de determinada característica orográfica, el por qué de un toponímico, son solo un par de muestras de esta naturaleza. El distanciamiento, particularmente temporal, en estos casos hace imposible o difícil la verificación tan apetecida en la actualidad. El mito aquí aprovecha su naturaleza primordialmente discursiva: crea una realidad discursiva cuya base se encuentra en el principio de verosimilitud.

La verosimilitud es fundamental en el mito. En los aitía, la realidad explicada habría sido el consecuente en una estructura lógica, pero aquí se erige como la verificación del aserto mítico. La validez del mito, dado su carácter argumentativo, reside en el consecuente, en la conclusión. El mito, cuando explica una realidad del mundo, incurre en una petición de principio: su verdad se sustenta en la comprobación de un hecho que precisamente trata de explicar. Así, la fundación mítica de una ciudad se verifica por la existencia de esa ciudad.

Este vicio del pensamiento proviene del carácter histórico que pretende: el mito se presenta como realidad y parte de la realidad histórica del ser humano.

De esta manera, el carácter explicativo que pueda tener el mito se expresa no por una implicación material, que lo condenaría al ámbito de las falacias no formales, sino por una implicación estricta, es decir, aquellas implicaciones lógicas que solo son verdaderas cuando el antecedente y el consecuente son verdaderos. En cambio, el enunciado de una implicación material es verdadero cuando el antecedente es falso (cosa que no es posible en la implicación material). Esta asociación obedece a que en el mito el consecuente, es decir, el fenómeno explicado, es "verdadero" (está a la "vista" del creyente) y el antecedente (su explicación mítica) se asume como cierta.

Un requerimiento fundamental que ha de satisfacerse, en este sentido, es su consistencia, su coherencia. Así lo reconoce Menandro el Rétor al referirse a la hímnica ficticia:

Hay que tener cuidados primero de inventar no de manera incongruente, sino con coherencia; y eso se puede conseguir, si la invención se configura a partir de ellos y no queda desligada; después, de no hacer la invención con mal gusto, sino de manera atractiva y decorosa, como lo de las Musas, hijas de la Memoria, o cualquier cosa así - y es que algunas incluso son desagradables de oír, como lo de que Atenea salió de la cabeza de Zeus; pues eso no es correcto, a no ser que se haya dicho mediante alegoría y con relación a alguna otra cosa; de otra manera, se hace una invención de mal gusto -; 
después de basar las pruebas de lo que inventemos en algo verdadero, como nosotros hemos hecho, y con frecuencia Homero. Además, hay que procurar que los himnos ficticios sean coherentes consigo mismos y no conlleven contradicciones o discrepancias, como en el mito aquel en que Zeus nació antes que todos los seres y es padre de toda divinidad, y se casó con Temis, que era antaño mujer de Crono. Pues si era anterior a todo, también anterior a Temis, pero si Temis era anterior a Zeus, no sería él anterior a todo. (1996, p. 105-106, 341.19-342.4)

Esta cita ilustra sobremanera el requerimiento de consistencia en la narración mítica.

El mito se nutre del principio de la verosimilitud: asentado en el universo de lo sobrenatural como premisa mayor, las leyes físicas de espacio y tiempo son superadas, solo se ve sometido a las leyes de su lógica interna.

Ahora bien, se han presentado ejemplos de tres categorías de la mitografía griega: el sueño, el ejemplo de una conducta y la causa de algo. Estas tres categorías coinciden con los tres esquemas argumentativos expuestos por van Eemeren y Grootendorst en su obra Argumentación, comunicación y falacias - Una perspectiva pragma-dialéctica (al respecto puede consultarse (van Eemeren y Grootendorst, 2002, p. 118), que aquí nos permitimos denominar así:

a) argumentación por sintomaticidad,

b) argumentación por similaridad y,

c) argumentación por instrumentalidad.

La primera de ellas se basa en una relación de concomitancia entre la aceptabilidad de las premisas y la conclusión; la segunda, en una relación analógica y, la última, en una causal. En palabras de estos autores:

En el primer tipo de argumentación, el hablante trata de convencer a su interlocutor mostrando que algo es sintomático de alguna otra cosa. Este tipo de argumentación está basado en un esquema argumentativo en que la aceptabilidad de las premisas se transfiere a la conclusión haciendo comprender que existe una relación de concomitancia entre lo que se afirma en el argumento y lo que se afirma en el punto de vista. La 
argumentación es presentada como si fuera una expresión, un fenómeno, un signo o algún otro tipo de síntoma de lo que se afirma en el punto de vista. (2002, p. 116).

Grosso modo permiten comprender las formas básicas de argumentación en un ambiente mítico.

Señales, sueños, eventos naturales, coincidencias... son interpretados cotidianamente como mensajes de la divinidad, síntomas o indicios de su voluntad.

Por su parte, las experiencias en la vida de héroes, santos, Cristo, Mahoma, Buda... llaman imperativamente a ser imitadas, a ser seguidas, para que el creyente se asemeje a su modelo en este proceso.

Finalmente, tal y como se indicó oportunamente, gran parte de los mitos tienen carácter etiológico, por lo que ofrecen una explicación “causal”, lato sensu, del universo.

Es evidente que el valor argumentativo de los mitos está en función del contexto en el que se empleen. De esta manera, uno es el valor ad intra respecto de un grupo que comulgue con el sistema de creencias en el que se inserta, y otro ad extra. En el primero, refuerza, valida y transmite el sistema. En el segundo, en cambio, su aceptación dependerá del sistema de referencia que se asuma.

De lo anterior se colige que el mito fue un arma dialéctica en la antigüedad. Homero lo empleó en numerosas discusiones entre sus personajes; mientras que Hesíodo, los poetas trágicos y los líricos también aprovecharon el valor ejemplar del mito como estrategia de argumentación.

Sin embargo, su valor estaba circunscrito al medio en que se desarrollaba, tal y como muestra el siguiente pasaje del Dulcitius de Hrotsvitha, monja erudita de fines de la Alta Edad Media, en el que dramatiza el martirio de tres hermanas durante la persecución de Diocleciano:

Diocletianus: flecte cervicem diis et esto sororibus exemplum correctionis et causa liberationis.

Hirena: conquiniscant idolis, qui velint incurrere iram celsitonantis! ego quidem caput regali unguento delibutum non dehonestabo pedibus simulachrorum submittendo.| Diocletianus: cultura deorum non adducit inhonestatem, sed praecipuum honorem. 
Hirena: et quae inhonestas turpior, quae turpitudo maior, quam ut servus veneretur ut dominus?

Diocletianus: non suadeo tibi venerari servos, sed dominos principumque deos.

Hirena: nonne is est cuiusvis servus, qui ab artifice pretio comparatur ut empticius?

Diocletianus: huius praesumptio verbositatis tollenda est suppliciis.

Hirena: hoc optamus, hoc amplectimur, ut pro Christi amore suppliciis laceremur (2012, p. 1).

Diocleciano: Irene, aunque seas menor de edad, considero que eres grande en dignidad.

Irene: Muéstrame, por favor, ¿de qué manera?

Diocleciano: Inclina tu cerviz ante los dioses y, de esta manera, sé un ejemplo de corrección fraterna para tus hermanas, a la vez que causa de su liberación.

Irene: ¡Que inclinen sus cabezas ante los ídolos, quienes quieran despertar la ira del que hace tronar los cielos! Yo no deshonraré con un ungüento del rey mi cabeza ungida poniéndolo a los pies de los ídolos.

Diocleciano: El culto a los dioses no conduce a la vergüenza, sino al mayor honor.

Irene: Pero, dígame, ¿cuál vergüenza es más deshonrosa que esta, la mayor deshonra: el que a un esclavo se le venere como a su señor?

Diocleciano: No te aconsejo venerar a los esclavos, sino a los señores y principalmente a los dioses.

Irene: Pero, ¿no es siervo de un cualquiera quien, a un precio artificioso es comprado como mercancía?

Diocleciano: Tal presunción de locuacidad será llevada a los suplicios.

Irene: Eso escogemos, eso acogemos, para que por amor a Cristo seamos desgarradas (la traducción es del autor). 
Si bien los dos interlocutores participan de la visión mítica del mundo, sus visiones son distintas e irreconciliables. Esto produce que, lo que es una argumentación admisible para Irene, no lo sea para Diocleciano, experiencia que han sufrido todos los mártires, independientemente de cuál haya sido su credo, a lo largo de la historia de la humanidad; ya sea que se enfrentaran a jueces con creencias distintas o, incluso, agnósticos o ateos.

\section{La argumentación mítica en la visión racional del mundo}

En la sección anterior se ha mostrado que el mito posee una faceta argumentativa en contextos mitologizados. Ahora es pertinente examinar si tal faceta tiene validez también en una visión racionalista del universo, en la que:

La secularización y el "desencantamiento" de las cosmovisiones, con la pérdida que ello implica de su capacidad de orientar la acción, y de la tradición cultural en su conjunto, son la otra cara de la creciente "racionalidad" de la acción social. (Habermas, 1992, p. 54).

Esta etapa del pensamiento no es otra cosa que una forma distinta de dominio político sobre el discurso, en palabras de Habermas, así como lo fue su precedente.

La primera constatación es que el valor de verdad del mito ahora no es el mismo, ya que ha sido relativizado, si no anulado.

El mito ha sido objeto de un proceso de desvalorización argumentativa. Nótese que en cuanto "criterio de verdad", el mito se podía identificar con la verdad, por lo que era incuestionable.

La autoridad asociada también sufre este proceso, por lo que frases bíblicas, hechos de personajes famosos, la investidura de cierto grado de conocimiento y legitimación para su interpretación, por ejemplo, un sacerdote, un obispo, el Papa, o Jesús, ya no tienen valor per se.

La causalidad, por su parte, se ve sometida a otros parámetros, los cuales, difícilmente son satisfechos por los textos míticos.

El choque radical de ambas visiones en torno al mito como argumento se ilustra a cabalidad en las obras de Galileo Galilei, quien debió enfrentar sus observaciones científicas con la raigambre 
mítica de sus opositores clericales, quienes difícilmente aceptarían el carácter mítico del discurso del que partían.

Pareciera, pues, que el valor del mito sería meramente ornamental, al figurar en proemios, narraciones o conclusiones discursivas con aquel valor que Perelman y Olbrechs-Tyteca denominan comunión. De manera que se fortalezca la proximidad entre el orador y su público y, de esta manera, alcanzar el convencimiento de este último. Sin embargo, esto no es necesariamente así.

Platón parece haber problematizado esta situación en Político y ofrece una respuesta: para él, el mito no solo tiene valor argumentativo en contextos mitologizados, sino en la política, así se lee en esta obra:

Extranjero: - ¡Y bien! ¿A qué ciencia le concederemos, por lo tanto, el poder de persuadir a la muchedumbre y a la masa a través de la narración de historias, pero no a través de una enseñanza?

Joven Sócrates: - Para mí está claro que también esto hay que asignárselo a la retórica.

Extranjero: - Y el decidir si es por medio de la persuasión o bien recurriendo a algún tipo de violencia como debe llevarse a cabo alguna acción en relación con alguna persona o bien dejarla en paz, esto, por su parte, ¿a qué ciencia se lo atribuiremos?

Joven Sócrates: - A aquella que gobierna el arte persuasivo y el estar oratorio.

Extranjero: - Y ella no podría ser otra - según creo - que la competencia propia del político.

Joven Sócrates: - ¿Qué bien te has expresado!

Extranjero: - Así parece que la retórica ha quedado rápidamente separada de la política, como una especie diferente de ésta y que está, sin duda, a su servicio.

Joven Sócrates: - Sí. (1988, p. 603, 304c-d)

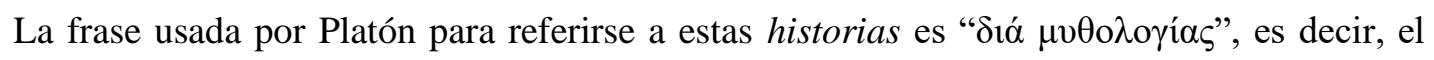
político persuade al pueblo mediante mitos. 
Los mitólogos, ya sean los alegoristas, evemeristas, mitólogos comparados, simbolistas, funcionalistas, estructurales, mitocríticos... manifiestan también una aplicación racional y argumentativa en el ámbito de los mitos al construir lo que conocemos como "mitología", a saber:

(...) la interpretación y el estudio de los mitos. Es una tarea hermenéutica que ya fue practicada por los filósofos griegos y que cuenta con una larga tradición. Es decir, en esta acepción, la mitología trata de descubrir y explicitar todos los significados que revelan los mitos una vez sometidos al examen de la razón, mitos analizados, glosados y traducidos al lenguaje más racional del lógos. (García Gual, 2006, p. 309)

Por su parte, ya se ha adelantado que las construcciones teológicas en gran medida pretenden reconciliar los criterios de racionalidad con la visión mítica al aplicar estos principios al examen y comprensión de sus creencias. Esto puede ilustrarse en el famoso argumento de la apuesta, insinuado, entre otros, por Arnobio, retórico y orador nativo de Sicca (la actual el-Kef, en Túnez), que no es otra cosa que una respuesta al dilema existente entre creer o no creer en Dios, argumento que el historiador de la literatura Santiago Prampolini (1955) nos transmite:

(...) Por una parte, ningún peligro si lo porvenir no se realiza; por otra, el máximo de los daños, la pérdida de la salvación, si llegado el momento aparece que la promesa no era falaz. $(66$, n. 86$)$

Tal argumento puede formalizarse de la siguiente manera: sea "p" la proposición "lo porvenir se realiza" y "q", "hay peligro para el alma"; de esta manera, la premisa "si lo porvenir no se realiza, entonces no hay peligro para el alma" se representa así:

$$
\neg \mathrm{p} \rightarrow \neg \mathrm{q}
$$

Por su parte, la segunda afirmación equivale aproximadamente a "si lo porvenir se realiza, entonces hay peligro para el alma", que se representa de la siguiente manera:

$$
\mathrm{p} \rightarrow \mathrm{q}
$$

Ante esta situación se tiene que "lo porvenir se realiza" o "lo porvenir no se realiza"- (p v $\neg$ p), en donde "v" representa la disyunción-; por lo tanto "hay peligro para el alma" o "no hay peligro para el alma"-(q v $\neg q)$-, que es un argumento válido, conocido como dilema. 
Un nivel argumentativo de calidad semejante o superior se descubre en textos atribuidos a Gorgias de Leontinos, se trata de su Defensa de Palamedes y el Encomio a Elena.

En el curso del primero, Palamedes se dirige a los jueces de la Asamblea con estas palabras:

Pero, si ha hecho su acusación por presumir que las cosas sucedieron así, voy a demostraros que está equivocado mediante una doble argumentación: un acto de esta naturaleza, yo, aunque hubiera querido cometerlo, no habría podido, y, si hubiera podido, no habría querido. (1980, p. 168)

Aunque este argumento involucra lógica modal y epistémica, puede simplificarse su examen mediante el cálculo proposicional. De esta manera, si "p" representa "poder hacer algo" y “q”, "querer hacer algo", tenemos la representación:

$$
(\mathrm{q} \rightarrow \neg \mathrm{p}) \cdot(\mathrm{p} \rightarrow \neg \mathrm{q})
$$

Se trata de una tautología, ya que, por la regla de transposición (citada supra), "q $\rightarrow \neg p$ ” es equivalente a " $\mathrm{p} \rightarrow \neg \mathrm{q}$ ", de donde se colige la brillantez de la defensa propuesta por Palamedes.

Gorgias, así como numerosos retóricos y autores, se permiten incorporar argumentos complejos en sus narraciones míticas; empero, este grupo no comulga necesariamente de la visión mítica del mundo. Aquí el mito se usa con un propósito didáctico o, en el mejor de los casos, es un mero ejercicio para mostrar la realización de argumentos en una defensa judicial.

Boecio, así como otros autores, ejemplifica sobremanera otra de sus funciones argumentativas. En una mezcla de poesía y prosa, que vincula esta producción con la sátira menipea, llevándola a una de las expresiones de mayor dignidad de este género, incorpora referencias míticas en su exposición. Por ejemplo, al tratar del tema del hombre y la Fortuna, ante el cual la tesis boeciana es que no debemos estimar en tanto valor a esta última. En el poema final cita eventos de la época heroica:

Durante una guerra de diez años

el vengador hijo de Atreo

sembró de ruinas Frigia

para castigar el rapto de la mujer de su hermano. 
Fue él quien lanzó al mar la flota de Grecia,

pero pagó los vientos al precio de su propia sangre:

dejando a un lado su condición de padre,

hizo de funesto sacerdote al ofrecer a la diosa

el cuello de su desgraciada hija.

El héroe de Ítaca lloró a sus desaparecidos compañeros

cuando Polifemo, recostado en su inmenso antro,

los engulló en su monstruoso vientre.

Pero el cíclope, furioso por haber perdido la vista,

pagó con lágrimas la alegría del festín.

Los duros trabajos celebran la gloria de Hércules. (2010, p. 159-160)

La serie de antítesis vientos propicios/vida de la hija, héroe de Ítaca/lágrimas por los compañeros; alegría del festín/furia por perder la vista pone de relieve la efímera condición humana y su fragilidad ante las vicisitudes de la Fortuna. El vector argumentativo (pues todo enunciado en este campo tiene un sentido y una "fuerza" o magnitud) se dirige a fundamentar la tesis de que la Fortuna es cambiante y no hay que apegarse demasiado a ella. En cuanto argumento, ha de calificarse como exempla, aunque con un papel muy distinto al de la sección anterior.

Ciertamente, en cuanto exemplum, el mito no solo es admisible en un contexto mítico, sino también en el racional. Aquí el mito sirve para ilustrar una regla de conducta, un principio, y, a través de una inducción se pretende validar una tesis. Ahora bien, el exemplum no solo es figura retórica, también es un tipo de argumento y, además, puede formar parte de una secuencia argumentativa (sobre el tema puede consultarse Campos, 2012, p. 501).

Otra función importante que podría tener el mito tiene que ver con los tres principios retóricos de la composición discursiva: la claridad. A través de una imagen mítica puede hacerse más asequible al auditorio la comprensión de un argumento. 
Al privilegiar los argumentos racionales, el valor estratégico del mito se transformó: Platón lo comprueba cuando la mayor parte de sus mitos son inventados y ubicados estratégicamente, un valor instrumental aprovechado asimismo por la escuela de los alegoristas, ya que el mito no solo sirve como exemplum, sino como analogía. Tal utilidad fue percibida por los retóricos griegos al hablar de la fábula ( $\mu$ v́os, en griego). Por ejemplo, en sus Ejercicios de retórica Aftonio indica:

La fábula procede de los poetas, pero ha resultado también común en los oradores a causa de la moraleja que contiene. Una fábula es una composición falsa que simboliza una verdad. (1991, p. 215, 1)

La fábula se configura como un símbolo para expresar un pensamiento. Esta propiedad aparece estrechamente relacionada con el valor argumentativo de las figuras retóricas, ya que, entre otros rasgos, pueden contribuir con estas características (sobre el tema puede consultarse Campos 2012, p. 501).

Para Álvaro Vallejo Campos, por su parte:

En contraposición a la mera alegoría, este es el carácter específico de los mitos escatológicos: su intento de expresar algo que no puede decirse en el lenguaje del logos, porque está más allá de toda verificación y de toda argumentación racional. (2005, p. 121)

Este rasgo, identificado por Vallejo en esta categoría de mitos, en realidad se extiende a todos ellos y es consecuencia directa de la faceta argumentativa de las figuras retóricas. En este sentido, el mito se troca en retórica, algo que Nietzsche había destacado:

El componente mítico en los diálogos es el retórico: el mito tiene como contenido lo verosímil; su objetivo no es, por consiguiente, enseñar, sino suscitar en los oyentes una $\delta o ́ \xi \alpha$ [opinión], por lo tanto $\pi \varepsilon i ́ \theta \varepsilon ı v$ [persuadir]. Los mitos pertenecen a la $\pi \alpha \gamma \kappa \alpha ́ \lambda \eta \pi \alpha ı \delta$ ió [a un juego pueril]: tanto las composiciones retóricas como las escritas son fabricadas para divertirse. La verdad no puede expresarse ni en una forma escrita ni en una retórica. Lo mítico y lo retórico se utilizan cuando la brevedad del tiempo impide una enseñanza científica. Traer a colación algunos testimonios es un procedimiento retórico; de este modo, los mitos platónicos son introducidos a través de una apelación a testimonio (2000, p. 84,420$)$ 
Al examinar el papel del mito en el Gorgias de Platón, Vallejo Campos estima que:

Pero si las amenazas de Calicles son las razones, internas a la propia obra, que exigen la presencia del mito para decir la última palabra en el conflicto entre filosofía y retórica o entre justicia y poder, el mito es reclamado también por la situación del lector. Cuando éste tenía el Gorgias entre sus manos sabía que Sócrates, efectivamente, había perecido injustamente condenado. A lo largo de la obra se argumenta en favor de los ideales de justicia y moderación sobre la base de un concepto terreno de la existencia y del alma. Pero esa argumentación, a los ojos del lector, se habría revelado insuficiente y Platón se ve obligado a buscar en la otra vida una nueva dimensión de la existencia humana sin la cual la teoría socrática del alma nos conduciría a un heroísmo trágico muy poco convincente (ibid, p. 123).

Lo anterior es corolario del pensamiento platónico: desde un punto de vista retórico, el discurso debe aproximarse al "tipo de alma" del lector, solo así le será inteligible. Este es, en última instancia, el motivo por el cual se inserta el discurso mítico con carácter argumentativo, un valor que el propio Platón reconoce en sus diálogos, tal y como se citó al inicio.

Concluye el presente examen de las relaciones existentes entre el mito y la argumentación invirtiendo los términos de la interrogación: ¿qué vínculo existe entre la argumentación y el mito propiamente dicho?, pregunta a la que puede responderse con el Himno Homérico a Hermes, un texto en el que una secuencia argumentativa forma parte del propio mito. El astuto y pequeño Hermes había robado cincuenta vacas a Apolo. Cuando se ve interpelado por este último dios, niega el hecho y arguye:

— ¡Hijo de Leto! ¿Qué crueles palabras son éstas que me has dirigido? ¿Y qué es eso de que vienes aquí en busca de tus camperas vacas? No las vi, no me enteré de ello, ni oí el relato de otro. Ni podría denunciarlo, ni podría ganarme siquiera una recompensa por la denuncia. Tampoco tengo el aspecto de un varón robusto, como para ladrón de vacas. Ese no es asunto mío. Antes me interesan otras cosas: me interesa el sueño, la leche de mi madre, tener pañales en torno a mis hombros y los baños calientes. ¿Que nadie sepa de dónde se produjo esa disputa! sin duda sería un gran motivo de asombro entre los inmortales que un niño recién nacido atravesara la puerta de la casa con camperas vacas. Lo que dices es un disparate. Nací ayer. Mis pies son débiles y bajo ellos la tierra, dura. (1988, p. 161-162, 260-274) 
La defensa de Hermes presenta varios argumentos:

a) No las vi, no me enteré de ello, ni oí el relato de otro.

b) No tengo el aspecto de un varón robusto.

c) No me interesan las vacas.

d) Nací ayer y mis pies son débiles.

Aunque la argumentación del pequeño dios no exprese los argumentos de manera completa, es posible reconstruirlos, ya que, básicamente, parte de una proposición condicional (omitida en el discurso), cuyo consecuente se niega para, mediante un modus tollens, negar el antecedente. Por ejemplo, pueden construirse los siguientes argumentos:

a.a) Si se han robado las vacas, entonces el ladrón debe conocer del robo;

b.a) pero yo no conozco del robo,

c.a) por lo tanto, yo no he robado las vacas.

a.b) Si se han robado las vacas, entonces el ladrón debe ser robusto;

b.b) pero no soy robusto,

c.b) por lo tanto, yo no he robado las vacas.

a.c) Si se han robado las vacas, entonces quien lo hizo estaba interesado en las vacas;

b.c) pero no estoy interesado en las vacas,

c.c) por lo tanto, yo no he robado las vacas.

La última argumentación, en cambio, corresponde a un modus ponens:

a.d) Si soy un recién nacido, entonces no puedo ser el ladrón de las vacas;

b.d) soy un recién nacido,

c.b) por lo tanto, yo no puedo ser el ladrón de las vacas.

Fácilmente el lector reconocerá que los argumentos deberían ser más elaborados, pero, por razones de simplificación, se ha recurrido a enunciarlos de esta manera, la cual permite apreciar que en la argumentación de Hermes se aplican sencillas reglas lógicas. 
Este ejemplo muestra un último eslabón en el presente examen: que los mitos también pueden incorporar argumentos en su propia narración, no ya como ejercicios retóricos (como en Gorgias), sino como expresión del sistema de creencias.

\section{Conclusiones: los valores de la argumentación mítica}

Producto de este trabajo, ha podido mostrarse cómo el valor del mito en un proceso argumentativo se ve afectado por el sistema de creencias de quienes intervienen en la argumentación. En efecto, su valor está en función de la visión de mundo de los participantes. En este artículo se identificaron dos visiones principales: la visión mítica el mundo y la visión racionalista del mundo. A pesar de su naturaleza diversa, pudo comprobarse que, en relación con el mito, ambas visiones comparten un uso fundamental, el exemplum.

Ahora bien, como parte de la serie de relaciones y valores que pueden establecerse entre el mito y la argumentación se identificaron las siguientes: a) el mito puede ser el criterio de verdad, b) el mito puede ser fuente de autoridad, c) existe un exemplum mítico, d) el mito puede expresar una relación de causalidad, e) el mito puede expresar sintomaticidad (las cuales corresponden a la visión mítica del mundo), f) el mito puede cumplir una función de ornato, g) el mito puede ayudar a clarificar la tesis o la argumentación de manera alegórica o analógica, h) el mito puede fungir como recurso didáctico; e i) el mito puede contener secuencias argumentativas (que, junto con el exemplum, se han asociado a la visión racionalista del mundo).

Se espera que este breve aporte pueda ser empleado en la docencia al examinar textos literarios con contenido mítico, no solo a nivel universitario, sino colegial. En este último, vale la pena recordar, recientemente se ha incorporado la lógica como ámbito de estudio en relación con la literatura.

\section{Bibliografía}

Apolodoro. (2004). Biblioteca mitológica. (1ª Ed.). Madrid: Alianza Editorial, S. A.

Boecio. (2010. La consolación de la Filosofía. (5 reimpresión). Madrid: Alianza Editorial, S. A.

Calímaco. (1980). Himnos, epigramas y fragmentos. (1 $1^{\text {a }}$ reimpresión). Madrid: Editorial Gredos, S.

A. 
Camacho Naranjo, Luis. (2009). Lectura inteligente: la lógica y la literatura en la enseñanza del español. San José, Costa Rica: Ministerio de Educación Pública.

Campos Vargas, Henry. (2012). "El valor argumentativo de las figuras retórica: primera parte". Revista de Ciencias Económicas, 30 (1), 499-506.

Gandeshemensis, Hrosvitha. (2012). Dulcitius. Recuperado de http://www.hsaugsburg.de/ harsch/Chronologia/Lspost10/Hrotsvitha/hro_dr02.html. Consulta: 1 de septiembre del 2012.

García Gual, Carlos. (2006). Introducción a la mitología griega. Edición ilustrada y ampliada. Madrid: Alianza Editorial, S. A.

Protágora, Gorgias.(1980). Fragmentos y testimonios. 1ª. Ed.). Buenos Aires: Ediciones Orbis, S. A. Habermas, Jurgen. (1992). Ciencia y técnica como "ideología". (2ª Ed.). Madrid: Editorial Tecnos, S. A.

Homero. (1995). Ilíada. Edición de Antonio López Eire. Madrid: Ediciones Cátedra, S. A.

Homero. (1988). Himnos Homéricos. La "Batracomiomaquia". Madrid: Editorial Gredos, S. A.

Lo Cascio, Vincenzo. (1998). Gramática de la argumentación. Madrid: Alianza Editorial, S. A.

Menandro el Rétor. (1996). Dos Tratados de Retórica Epidíctica. Madrid: Editorial Gredos, S. A.

Nietzsche, Friedrich. (2000). "Descripción de la retórica antigua". En Escritos sobre retórica. Madrid: Editorial Trotta, 81-107 / 415-442.

Ovidio. (1997). Metamorfosis. Madrid: Ediciones Cátedra, S. A.

Platón. (1988). Diálogos V. Parménides, Teeteto, Sofista, Político. Madrid: Editorial Gredos, S. A.

Plauto. (1988). Aulularia y Poenulus. (2 $2^{\mathrm{a}}$. Ed.) revisada por Víctor José Herrero. Madrid: Editorial Gredos, S. A.

Prampolini, Santiago. (1955). Historia Universal de la Literatura III. (2ª Ed.). Buenos Aires: U.T.E.H.A. 
Rivera García, Antonio. (2010). "Hans Blumenberg: mito, metáfora absoluta y filosofía política". Ingenium. Revista de Historia del Pensamiento Moderno, (4), 145-165.

Teón, Hermógenes, Aftonio. (1991). Ejercicios de retórica. Buenos Aires: Editorial Gredos, S. A.

Van Eemeren, Frans H. y Grootendorst, Rob. (2002). Argumentación, comunicación y falacias.

Una perspectiva pragma-dialéctica. (2 ${ }^{\mathrm{a}}$. Ed.). Santiago, Chile: Ediciones Universidad Católica de Chile.

Vallejo Campos, Álvaro. (2005). "Escatología y retórica en Platón". Revista de Filosofía, 30 (1), 117-134.

Vico, Giambattista. (1985). Ciencia nueva (vol. I) (edición de J.M. Bermudo). Madrid: Ediciones Orbis, S. A.

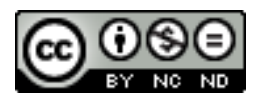

Esta obra está bajo una licencia de Creative Commons Reconocimiento-NoComercial-SinObraDerivada 4.0 Internacional. 